solution. Mr. Watkinson hoped that the final decision, which vitally affected air safety, would be taken on proper technical grounds and not on grounds subject to pressure, national prestige or any other consideration than that of the safety of passengers in the air. Mr. Watkinson deprecated the lobbying that had occurred and agreed that, as neither system was fully proved, it would be wise to leave the decision for a period for further technical experience to be accumulated.

\section{Research Associations}

IN answering questions regarding the British Hat and Allied Feltmakers Research Association in the House of Commons on March 17, the Parliamentary Secretary to the Ministry of Works, Mr. H. Nicholls, said that the Department of Scientific and Industrial Research had recently rejected the idea of a special grant to the Association in view of its development of No. 11 antishock felt in the production of protective caps for motorists and other road users. The Road Research Laboratory had been consulted by a hat manufacturer and had suggested that felt might be used in protective hats, and the manufacturer and the Research Association had cooperated with the Laboratory in selecting a quality, density and thickness of felt for antishock protection; but he stressed that such felt hats were no substitute for the motor cyclists' crash helmets, although they undoubtedly offered some protection. In reply to a further question regarding facilities in the Department of Scientific and Industrial Research for assisting in the choice of scientific instruments, $\mathrm{Mr}$. Nicholls said that an instrument inquiry service is provided at the British Scientific Instrument Research Association and is largely financed by a contribution from the Association and an equal grant from the Department of Scientific and Industrial Research. Inquiries were at present running at the rate of 2,200 a year. The Research Association had a working party on instrument design which, inter alia, reviewed the specification, price and appearance of foreign instruments, and other research associations as well as the Department's research stations also designed new instruments.

\section{Memorial Meeting to Prof. F. Joliot-Curie}

A memorial meeting for Prof. Frédéric JoliotCurie was held at Friends House, Euston Road, London, on January 22 . It was attended by many scientists invited by the Association of Scientific Workers and by the National Committee of Science for Peace. The chair was taken by Prof. C. L. Oakley, president of the Association of Scientific Workers, and the speakers were Prof. C. F. Powell, Dr. Pierre Biquard and Prof. J. D. Bernal.

Prof. Powell outlined the contribution made by Joliot and his wife, Irene Curie, towards the discovery of the neutron, leading to the discovery, in 1934, of artificial radioactivity, for which in 1935 he received the Nobel Prize for Chemistry. Dr. Pierre Biquard, secretary-general of the World Federation of Scientific Workers and a close friend of Joliot's, described the joy Joliot had expressed to him at having been able to add to the contribution of French science to man's knowledge. Dr. Biquard also spoke about the part played by Joliot in the French Resistance during the Nazi occupation, when he refused to leave his country and stayed to help defend it after arranging for the valuable stock of heavy water to be brought safely to Britain. Prof. Bernal described Joliot's work on the international level. In the 1930's he had been a member of the Anglo-French Scientific Committee which had laid the basis for the foundation in 1946 of the World Federation of Scientific Workers, of which he bocame the first president. He had also taken an active part, as a representative of France, in the foundation of Unesco. Later, in 1949, Joliot was chosen as president of the newly formed World Council of Peace, a post which he held until his death.

\section{International Journal of Radiation Biology}

International Journal of Radiation Biology and related studies in Physics, Chemistry and Medicine is the full title of a new journal, the first issue of which is dated January 1959 (1, No. 1. Pp. 104. Subscription per volume (4 issues) $75 s$., post paid ; price per part 20s. plus postage. London: Taylor and Francis, Ltd., 1959). The editor is Dr. W. M. Dale, of the Department of Biochemistry, Christie Hospital and Holt Radium Institute, Manchester, and to assist him there is a large editorial board with distinguished representatives from Europe, the United States, Australia and Japan; regrettably, the U.S.S.R. is not represented. The first paragraph of the editorial gives a concise description of its aims : "In this new journal we propose to bring together all interests concerned with the biological effects of ionizing radiations. The field we hope to cover will not, however, be a narrow one, for it will embrace any discipline--medicine, physies and chemistry, for example-which has a bearing on our main theme".

The introduction of a new journal invariably arouses mixed feelings. We experience apprehension at the thought of having to add yet another publication to our check list, but on referring to this list, we find, rather surprisingly, that this new journal is the first primarily concerned with the important and growing subject of radiation biology. In the past there has been a tendency to regard radiation biology either as an appendage of radiotherapy or as a highly specialized version of applied physies. These views are completely unjustified and the practitioners of medicine and physics are necessarily joined by radiation chemists, biochemists, eytologists and geneticists in a combined attack upon a highly complex set of problems. The ten original articles in the first issue illustrate this clearly and embrace each of the above-mentioned disciplines. The international scope is revealed by the fact that these ten articles originate from no fewer than seven different countries. Articles may bo submitted in English, French or German, accompanied by short summaries in all three languages; all articles in the first issue are, in fact, in English.

\section{Publications in Microform}

THE problem of providing adequate storage space for the ever-increasing number of publications in science and technology is one that constantly haunts librarians. For journals which may be consulted infrequently and for books of historic importance some form of microform storage appears to be in. evitable. The making of the most suitable types of microform materials itself raises problems of mechanics and storage and, for these and other reasons, librarians will welcome the enterprise of MicroMethods, Ltd., of East Ardsley, Wakefield, Yorks, which has issued extensive lists of journals that have already been issued in micro-card, micro-film or micro-fiche form. Other lists contain details of rare and out-of-print books which have also been produced 